\title{
Prinsip Kerja dan Teknologi OLED
}

\author{
Lukas B. Setyawan \\ Program Studi Teknik Elektro, \\ Fakultas Teknik Elektronika dan Komputer, \\ Universitas Kristen Satya Wacana, Salatiga \\ Email : lukas.setyawan@staff.uksw.edu
}

\begin{abstract}
Ringkasan
Devais opto-elektronik menggunakan bahan organik semakin banyak dibutuhkan dengan berbagai alasan. Devais dari bahan organik memiliki keuntungan dari segi harga dibanding devais inorganik. Sifat bahan organik yang memiliki kelenturan sangat sesuai untuk aplikasi tertentu seperti fabrikasi di atas landasan yang lentur. Bahan organik yang digunakan untuk membentuk OLED berhubungan dengan satu dari dua mekanisme terjadinya electroluminescence, yaitu fluorescene dan phosphorescence. Makalah ini menjelaskan mengenai bahan pembentuk OLED, struktur devais, diagram energi, dan cara pengangkutan elektron dan hole. Dijelaskan juga prinsip dasar Small Molecular OLED dan Polymer LED. Keunggulan yang dimiliki OLED mendorong penerapan OLED sebagai penampil terutama penampil papan layar datar.
\end{abstract}

Kata kunci: organic light-emitting diode, polymer light-emitting diode, electroluminescence, fluorescene, phosphorescence, flat panel display

\section{Pendahuluan}

OLED (Organic Light-Emitting Diode) adalah Light-Emitting Diode (LED) dimana lapisan emissive electroluminescent merupakan lembaran senyawa organik yang akan memancarkan cahaya bila dilalui arus elektrik. Lapisan bahan semikonduktor organik ini diletakkan di antara dua elektroda. Umumnya salah satu elektroda tersebut tembus pandang.

Devais OLED dibedakan menjadi dua macam, tergantung dari tipe lapisan organiknya, yaitu:

1. Devais small molecule (SMOLED)

2. Devais organic polymer (PLED atau LEP).

Devais small molecule difabrikasi menggunakan teknik evaporasi vakum, dengan meletakkan struktur polymer secara spin-casting atau memakai teknik cetak ink-jet. Sebutan OLED biasanya mengacu ke small-molecular OLED.

Struktur dasar OLED memiliki susunan seperti Gambar 1 dengan konfigurasi seperti Gambar 2. OLED memiliki ketebalan sebesar 100 sampai 500nanometer, sekitar 1/200 ketebalan rambut manusia. Lapisan bahan organik untuk menyusun OLED bisa 2 atau 3 lapis. 
Bagian-bagian penyusun OLED adalah sebagai berikut.

1. Substrat (plastik bening, kaca, foil)

Substrat digunakan sebagai tumpuan OLED. Sebagai substrat digunakan plastik, foil, atau kaca.

2. Anode (tembus pandang)

Anode mengambil elektron (menambah "hole" elektron) ketika arus mengalir melalui devais.

3. Lapisan konduktif

Lapisan ini terbuat dari molekul plastik organik yang berfungsi untuk mengangkut "hole" dari anode. Salah satu polymer konduktif yang digunakan pada OLED adalah polyaniline.

4. Lapisan emisif

Lapisan ini terbuat dari molekul plastik organik (berbeda dengan di lapisan konduktif) yang berfungsi untuk mengangkut elektron dari katode. Di lapisan ini cahaya dihasilkan. Salah satu polymer yang digunakan pada lapisan emisif adalah polyfluorene.

5. Katode (tembus pandang atau tidak tergantung pada jenis OLED)

Katode menyuntikkan elektron ketika arus mengalir melalui devais.

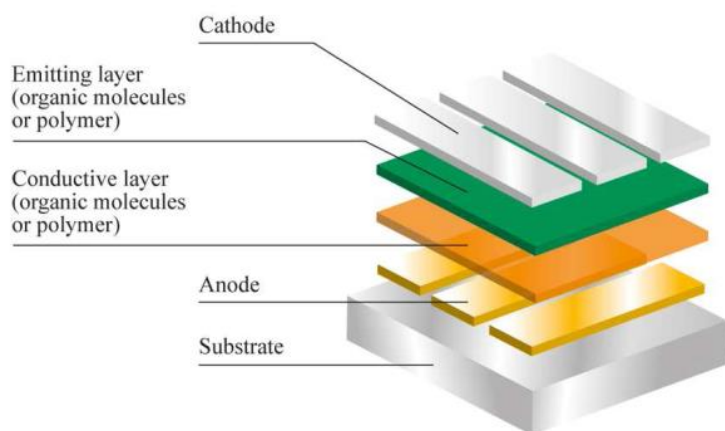

Gambar 1. Struktur dasar OLED

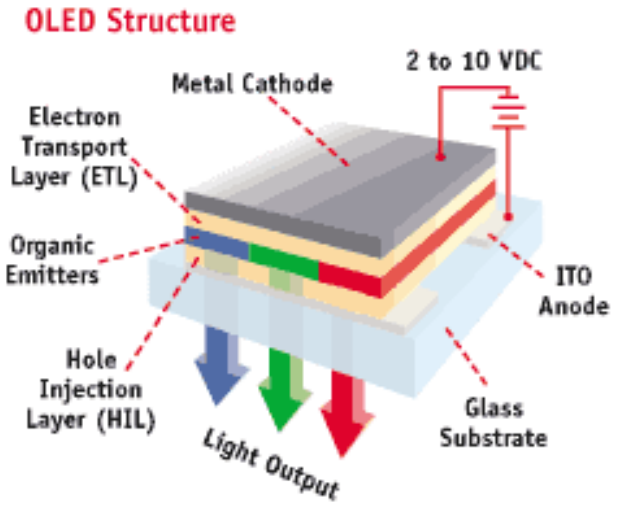

Gambar 2. Konfigurasi OLED

Struktur dasar OLED terdiri dari bahan organik yang diletakkan di antara katode dan anode, yang terbuat dari indium tin oxide (ITO) tembus pandang. Sedangkan bahan organik tersusun beberapa lapis lembaran tipis, meliputi Hole Transporting Layer (HTL), Emissive Layer (EML), dan Electron Transporting Layer (ETL). Dengan memberikan 
tegangan yang sesuai, hole dari anode akan masuk ke EML dan elektron dari katode akan masuk ke EML. Di dalam EML hole dan elektron bergabung sehingga terjadi electroluminescene. Bahan HTL, ETL, EML, dan pilihan elektrode merupakan faktor kunci yang menentukan kualitas OLED.

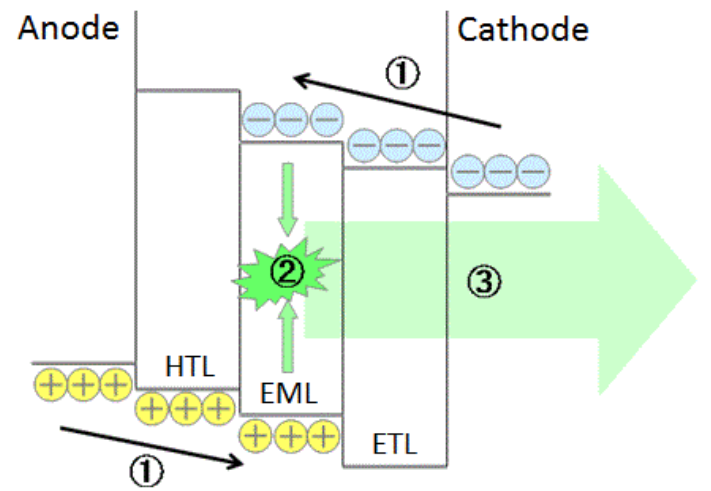

Gambar 3. Skema mekanisme electroluminescence pada OLED.

(1) Elektron (biru) dan hole (kuning) disuntikkan dari elektroda menuju lapisan emisif organik (EML).

(2) terbentuk pasangan elektron-hole atau exciton (hijau).

(3) rekombinasi exciton akan menyebabkan terjadinya emisi foton.

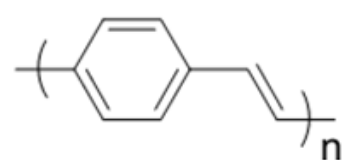

a

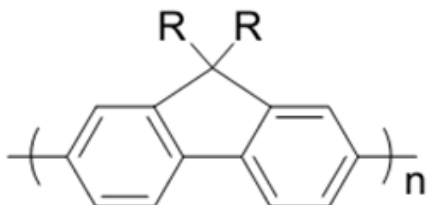

b

Gambar 4. Polymer yang paling banyak digunakan untuk menghasilkan electroluminescence pada OLED. (a) PPV (b) PFO
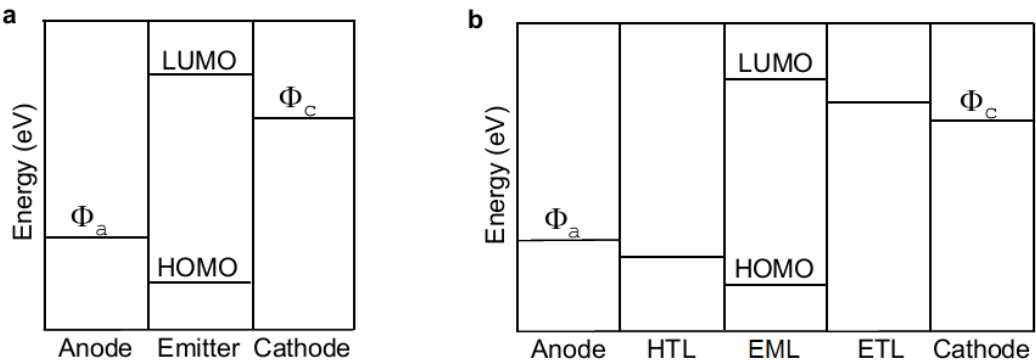

Gambar 5. Diagram energi level (a) OLED lapis tunggal (b) OLED lapis jamak dengan hole transporting layer (HTL) dan transporting layer (ETL) disisipi emissive layer (EML).

\section{Small-Molecular OLED}

Struktur diode p-n merupakan faktor penting untuk devais OLED. Struktur dasar SMOLED terdiri atas dua lapis lembaran tipis bahan organik, yaitu hole transport layer HTL (lapisan-p pada LED) dan electron transport layer - ETL (lapisan-n pada LED) yang disisipkan di antara anode dan katode (lihat Gambar 6). Kedua lapisan organik ini, masing-masing memiliki ketebalan sekitar $500 \AA$, merupakan media untuk mengangkut pembawa muatan menuju penghubung yang terbentuk di antara dua lapisan itu. 


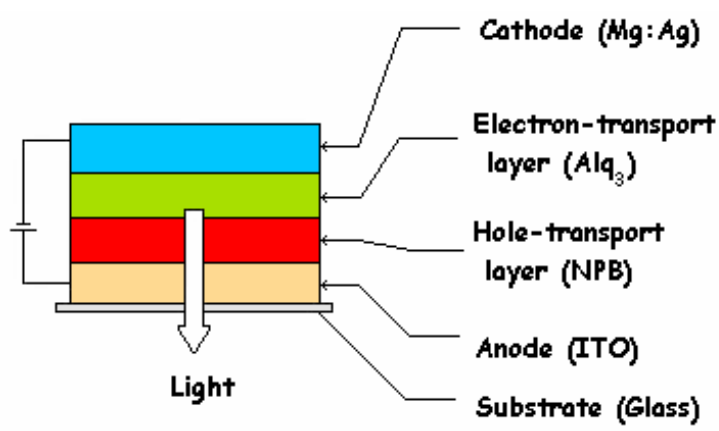

Gambar 6. Struktur dasar OLED terdiri atas lapisan hole-transport layer dan lapisan electron transport yang disisipkan di antara katode dan anode.

Salah satu struktur SMOLED paling dasar menggunakan bahan organik NPB (turunan dari naphthyl substituted benzidine) sebagai HTL dan $\mathrm{Alq}_{3}$ sebagai ETL. Pada struktur tipikal ini digunakan indium tin oxide (ITO) sebagai anode yang tembus pandang dan magnesium-doped silver (Mg:Ag) sebagai katode.

Pada saat diberikan tegangan, terjadi injeksi muatan elektron melalui katode dan hole melalui anode. Elektron akan diangkut menuju LUMO (Lowest Unoccupied Molecular Orbital) dari ETL, dan hole menuju HOMO (Highest Occupied Molecular Orbital) dari HTL. Kemudian terjadi rekombinasi elektron dan hole menyeberang batas dengan sebagian besar hole bergerak menuju $\mathrm{Alq}_{3}$ (Lihat Gambar 7). Exciton terbentuk pada $\mathrm{Alq}_{3}$ dan memancarkan cahaya fluroscence warna hijau.

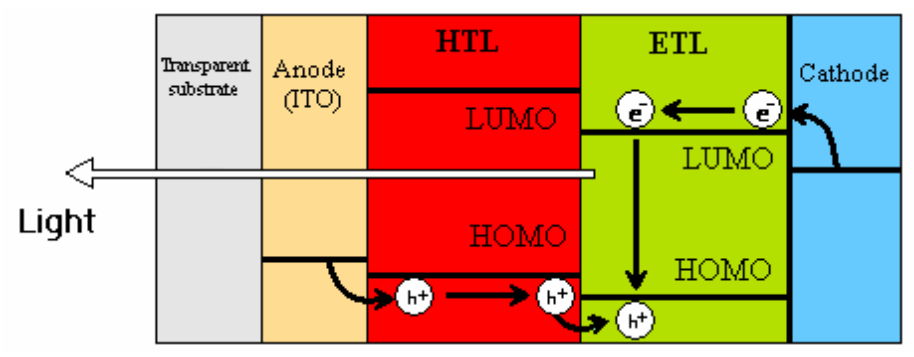

Gambar 7. Diagram energi pada SMOLED.

Salah satu struktur SMOLED paling dasar menggunakan bahan organik NPB (turunan dari naphthyl substituted benzidine) sebagai HTL dan $\mathrm{Alq}_{3}$ sebagai ETL. Pada struktur tipikal ini digunakan indium tin oxide (ITO) sebagai anode yang tembus pandang dan magnesium-doped silver (Mg:Ag) sebagai katode.

\section{PLED}

PLED tersusun atas satu atau lebih lapisan tipis semipenghantar organik yang disisipkan di antara dua elektroda, salah satu elektroda harus tembus pandang (transparan). (Gambar 8). 


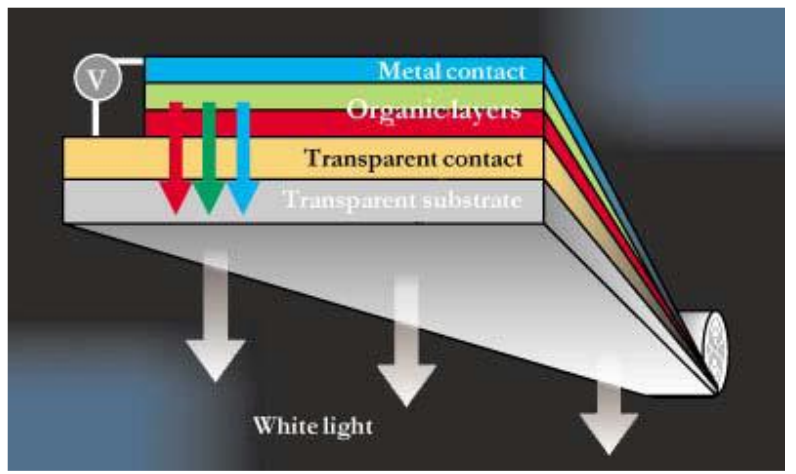

Gambar 8. Struktur dasar PLED (dua lapis)..

Diagram level energi untuk PLED lapis tunggal diperlihatkan oleh Gambar 9. PLED ini menggunakan PPV (poly-para-phenylene vinylene) dengan ketebalan sekitar 100nm dan ITO sebagai anode serta kalsium sebagai katode.

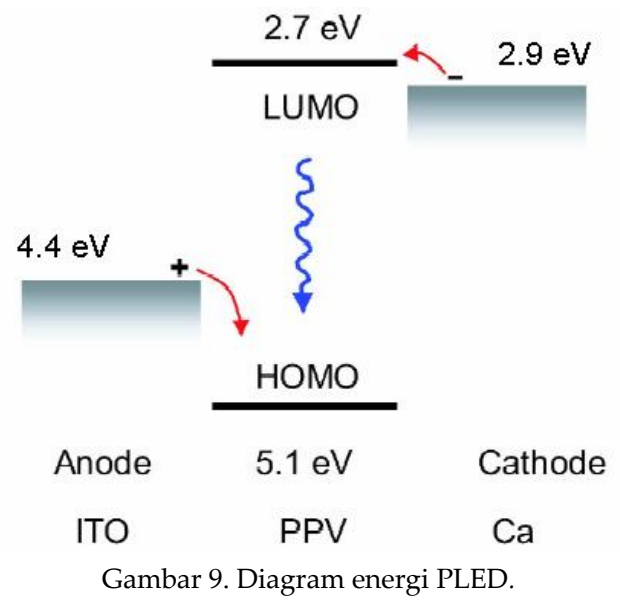

Saat diberikan pra-tegangan maju maka elektron diinjeksikan dari katode menuju LUMO polymer dan hole diinjeksikan dari anode menuju HOMO polymer. Elektron harus mampu mengatasi rintangan (electron injection barrier) yang ada di antara level Fermi dari kalsium dan level LUMO dari polymer. Untuk memperkecil rintangan biasanya digunakan logam yang memiliki work function rendah seperti $\mathrm{Mg}$ atau $\mathrm{Ca}$ agar didapat kontak ohmic. Bila terdapat kesesuaian energi antara katode dan LUMO berarti tidak banyak energi yang terbuang ketika elektron diinjeksikan. Demikian juga, untuk menjamin agar terjadi kontak ohmic saat hole diinjeksikan dari level Fermi ITO menuju HOMO polymer, maka ITO perlu diberi perlakuan dengan berbagai cara (misalnya dilakukan pembukaan untuk dibersihkan menggunakan ultraviolet-ozone) agar level Ferminya lebih rendah. Rintangan di sini disebut hole injection barrier.

\section{Kelebihan dan Kekurangan OLED}

\subsection{Kelebihan OLED}

\subsubsection{Lebih cepat}

Waktu tanggap OLED jauh lebih cepat dibanding penampil tipe lain. Dengan demikian layar penampil OLED memberikan kenyamanan kepada pengguna. Kelebihan 
ini mendorong semakin banyak penggunaan layar penampil OLED pada telepon genggam dan peralatan lain yang membutuhkan waktu tanggap yang lebih cepat.

\subsubsection{Pemakaian energi lebih efisien}

Pemakaian energi pada penampil OLED lebih kecil dibanding penampil LCD dan layar penampil lain. Penampil OLED tidak memerlukan lampu latar (backlit) dan ini merupakan kelebihan utama OLED untuk pemakaian perangkat portabel.

\subsubsection{Sudut pandang lebih lebar}

Sudut pandang merupakan masalah besar pada penampil layar datar. Penampil OLED memiliki sudut pandang sebesar 170 derajat karena OLED memancarkan cahaya serhingga memperlebar sudut pandang.

\subsubsection{Lentur}

Karena sifatnya lentur maka bisa dibuat penampil yang melengkung. Hal ini hanya dapat diperoleh dengan layar OLED.

\subsubsection{Awet}

Kelebihan lain dari OLED dibanding layar yang ada sebelumnya adalah lebih tahan lama. Kemungkinan rusak lebih kecil dibanding penampil LCD dan penampil lainnya.

\subsubsection{Lebih tipis}

Layar OLED lebih tipis dibanding layar LCD. Layar LCD dan layar plasma memiliki ketebalan beberapa inci sedangkan layar OLED ketebalannya hanya beberapa milimeter.

\subsubsection{Lebih murah}

Harga layar OLED lebih murah dibanding layar LCD.

\subsubsection{Nyaman di mata}

OLED lebih nyaman dipandang karena memiliki kontras, kecerahan, dan aspek warna lebih baik.

\subsection{Kekurangan OLED}

\subsubsection{Umur-pakai singkat}

Kekurangan utama OLED adalah layarnya tidak bisa dipakai dalam waktu lama. Dibanding LCD yang layarnya dirancang agar bisa dipakai dalam waktu lama. Dengan demikian layar penampil OLED memiliki kekurangan terbesar yaitu masalah utama dalam hal umur-pakai. Meskipun demikian, layar OLED tetap banyak digunakan pada layar telepon genggam karena sebagian besar pengguna telepon genggam menggunakan telepon kurang dari satu tahun sebelum ganti baru.

\subsubsection{Pengaruh paparan sinar matahari}

Kekurangan lain layar OLED adalah kesulitan melihat tampilan layar di bawah paparan sinar matahari langsung. Bila berada di ruangan yang terpapar sinar matahari langsung maka lebih susah membaca tampilan layar. 


\subsubsection{Sangat rentan terhadap air}

Layar OLED sangat rentan terhadap air. Layarnya tidak bisa bertahan meski hanya terkena tetesan air.

\subsubsection{Terpengaruh kelembaban}

Kelembaban akan selalu mempengaruhi lapisan organik dan mengakibatkan penurunan kualitas dan kerusakan pada penampil OLED.

\subsubsection{Konsumsi daya}

Untuk menampilkan gambar yang sebagian besar berwarna hitam, OLED membutuhkan daya sekitar 40\% dibandingkan LCD, secara keseluruhan gambar akan mengkonsumsi daya 60-80\% dari konsumsi daya LCD. Sementara untuk menampilkan gambar dengan latar belakang putih seperti dokumen atau website dibutuhkan daya tiga kali lebih besar.

\section{Aplikasi OLED}

Aplikasi OLED banyak digunakan untuk merealisasikan penampil digital di berbagai macam peralatan, contohnya layar televisi, monitor komputer, perangkat portabel seperti telpon genggam, digital media player, radio mobil, kamera digital, penerangan mobil, perangkat game genggam, dan PDA. Aplikasi portabel seperti itu lebih memilih OLED yang keluaran cahayanya sangat terang sehingga mudah terbaca di bawah terpaan sinar matahari dan irit pemakaian daya. Penelitian lebih mendalam telah menghasilkan OLED yang memiliki warna lebih natural, perangkat lebih efisien, dan kerjanya stabil.

OLED berkembang sangat cepat sebagai teknologi baru dalam bidang papan penampil dengan kemampuan OLED menampilkan warna lengkap, ongkos produksi makin murah, sudut pandang makin lebar, lebih lentur, konsumsi daya lebih kecil, kecerahan tampilan lebih baik, lebih tipis, dan lain-lain sehingga mampu menggantikan teknologi lain, seperti LCD dan LED.

OLED bisa dibentuk di atas plastik atau bahan lain yang memungkinkan berbagai aplikasi OLED untuk merealisasikan panel video ukuran raksasa, layar gulung untuk laptop, penampil otomotif, lampu penerangan rumah dan kantor, bahkan penampil yang bisa dipasang di kepala.

Penampil electroluminescence organik cukup kecil, gampang dipasang pada layar datar raksasa yang bisa digulung atau digantung rata dinding.

OLED dapat dikasifikasikan berdasar cara pembuatan dan tujuan penggunaannya menjadi beberapa tipe, sebagai berikut.

\subsection{Passive-matrix OLED (PMOLED)}

PMOLED memiliki lapisan organik dan lajur-lajur anode yang tersusun tegak lurus terhadap lajur-lajur katode. Persimpangan antara katode dan anode membentuk piksel dimana cahaya dipancarkan. Kecerahan setiap piksel sebanding dengan besarnya arus yang diberikan. Sirkit eksternal akan memberikan arus ke lajur anode dan katode yang dipilih untuk menentukan piksel mana yang dibuat on dan piksel mana yang tetap off. Fabrikasi PMOLED mudah dan murah tetapi memerlukan daya lebih besar dibanding OLED tipe lain meski tetap lebih sedikit dari konsumsi daya LCD dan LED. Penampil PMOLED memiliki kendala dalam hal resolusi dan ukuran (semakin banyak lajur garis 
semakin besar tegangan yang diperlukan). Penampil PMOLED biasanya berukuran kecil (paling besar 3 inci) dan digunakan untuk menampilkan data karakter atau ikon mini seperti pemakaian di pemutar MP3, tampilan tambahan di telepon genggam, dan lainlain.

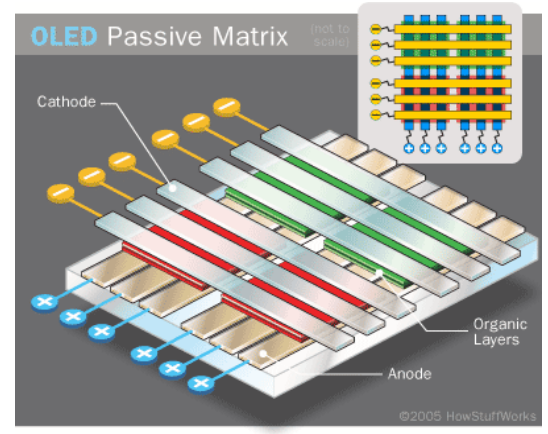

Gambar 10. Struktur Passive-Matrix OLED.

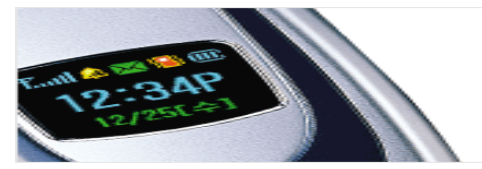

Gambar 11. Tampilan layar telepon genggam.

\subsection{Active-matrix OLED (AMOLED)}

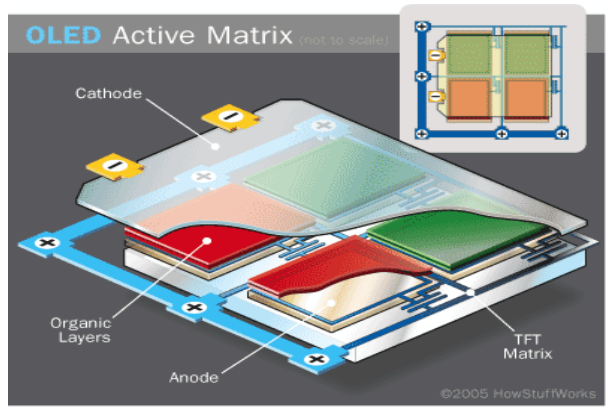

Gambar 12. Struktur Active-Matrix OLED.

AMOLED menggunakan katode, molekul organik, dan anode dalam bentuk lapisan penuh. Lapisan anode ditumpuk dengan bidang thin film transistor (TFT) secara paralel membentuk sebuah matriks. Ini akan membantu pada saat pensaklaran tiap piksel dalam kondisi keadaan on atau off sesuai dengan keinginan, sehingga terwujud sebuah gambar. Bila tidak diperlukan maka piksel dibuat off dan terlihat warna hitam pada penampil sehingga memperpanjang umur baterai devais. Dibanding dengan tipe lain, AMOLED paling kecil konsumsi dayanya serta memiliki refresh rate lebih cepat sehingga sangat cocok untuk aplikasi video. AMOLED paling baik digunakan untuk monitor komputer, TV layar lebar (Gambar 13), dan peraga elektronik atau billboard. 


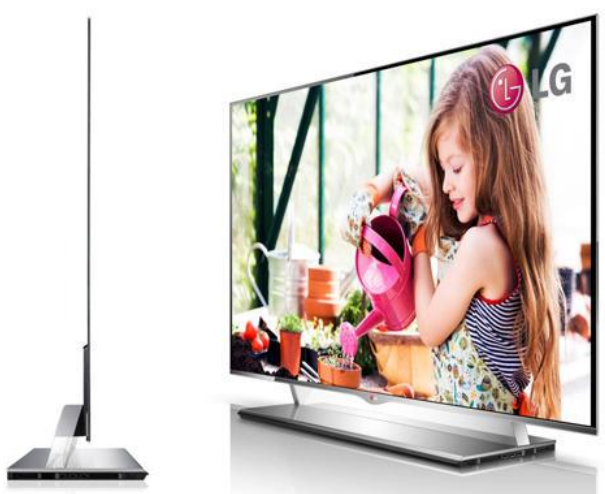

Gambar 13. Full-HD AMOLED TV (tebal 4mm dan berat hanya 3,5 kg).

\subsection{Transparent OLED}

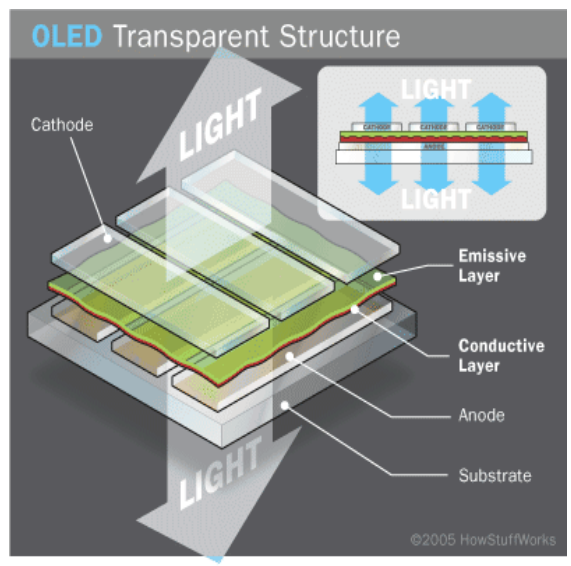

Gambar 14. Struktur Transparent OLED.

Transparent OLED (TOLED) hanya memiliki komponen tembus pandang: substrat, katode, dan anode. Ketika penampil TOLED dihidupkan akan memungkinkan cahaya melalui kedua arah. Tipe OLED ini dapat termasuk dalam kategori active dan passive matrix. Karena memiliki parameter tembus pandang pada kedua sisi maka dapat menampilkan tampilan pada bagian atas maupun bagian bawah. Devais ini memiliki kontras yang bagus meski dalam keadaan sinar matahari cerah sehingga dapat digunakan pada penampil head-up, laptop, telepon mobil, dan smart window.
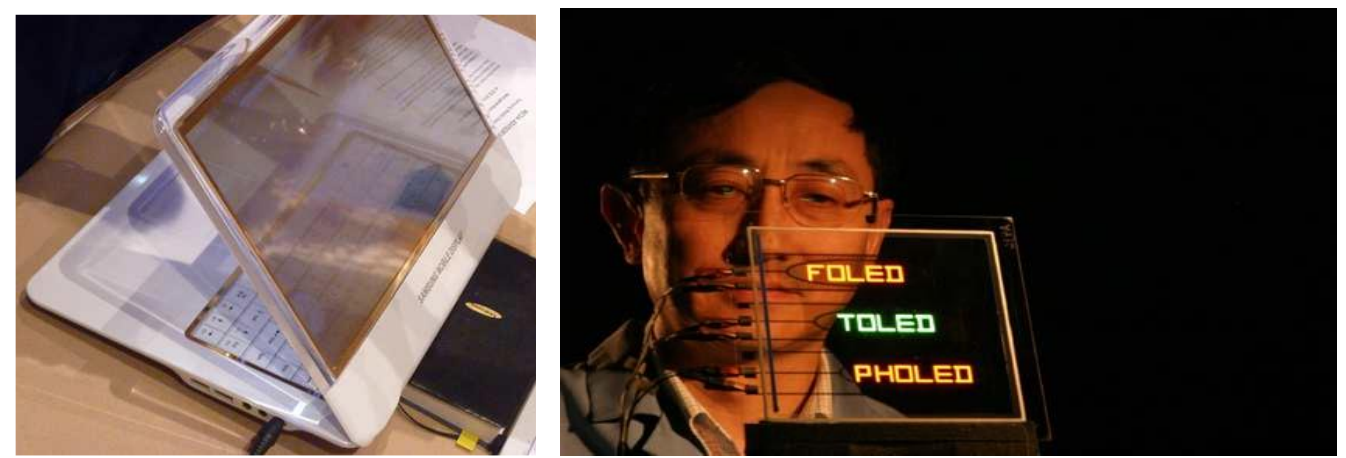

Gambar 15. Laptop Transparent OLED. 


\subsection{Top-emitting OLED}

Top-emitting OLED menggunakan tumpuan tidak tembus cahaya atau yang memantulkan cahaya. Top-emitting OLED sangat cocok untuk aplikasi active-matrix karena akan lebih mudah menggabungkan dengan landasan transistor yang tidak tembus pandang. Pabrikan memakai penampil top-emitting OLED untuk smart card.

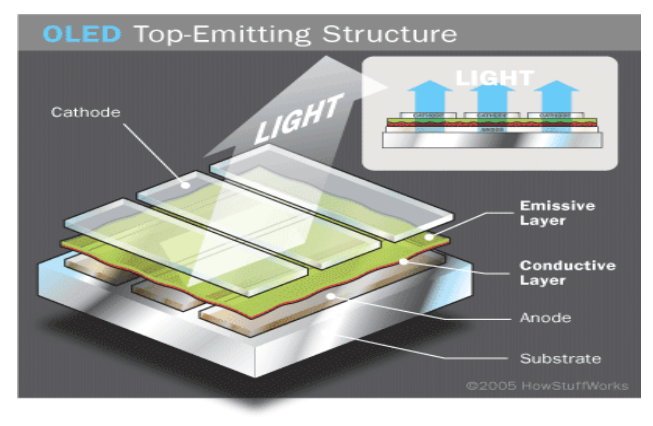

Gambar 16. Struktur Top-Emitting OLED.

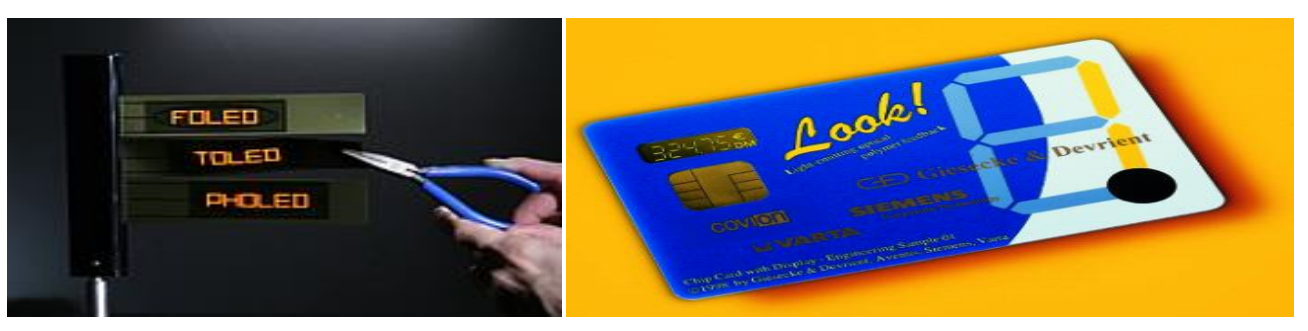

Gambar 17. Aplikasi Top-Emitting OLED.

\subsection{Foldable OLED}

Foldable OLED (FOLED) memiliki tumpuan terbuat dari foil metalik atau plastik yang sangat lentur. FOLED memiliki sifat lentur, sangat ringan, dan awet. Tipe ini digunakan terutama pada perangkat yang gampang pecah. Karena terbuat dari bahan yang kuat maka akan mengurangi kemungkinan rusak sehingga banyak digunakan pada perangkat GPS, telepon selular (Gambar 18a), dan TV layar lengkung raksasa (Gambar 18b). FOLED menawarkan resolusi gambar lebih bagus, waktu tanggap lebih cepat, dan gambar lebih kontras untuk televisi layar lengkung. Penampil foldable OLED dapat dilekatkan ke kain untuk membangkitkan kesan pakaian lebih "pintar", semacam pakaian untuk bertahan hidup di luar rumah yang dilengkapi dengan chip komputer, telepon selular, penerima GPS, dan penampil OLED dijahit ke pakaian.

\subsection{White OLED}

White OLED memiliki kualititas lampu pijar true-color dan memancarkan sinar putih sangat terang, lebih merata, lebih hemat energi dibandingkan dengan sinar yang dihasilkan oleh lampu fluoresen dan lampu pijar. Karena white OLED bisa direalisasikan di atas lembaran besar, murah, konsumsi daya rendah maka bisa dipakai sebagai pengganti lampu fluoresen dan sangat menghemat pemakaian energi untuk penerangan (Gambar 19a). White OLED sangat cocok untuk penerangan pada mobil (Gambar 19b) karena dapat menampilkan warna hitam pekat seperti layaknya lampu. 


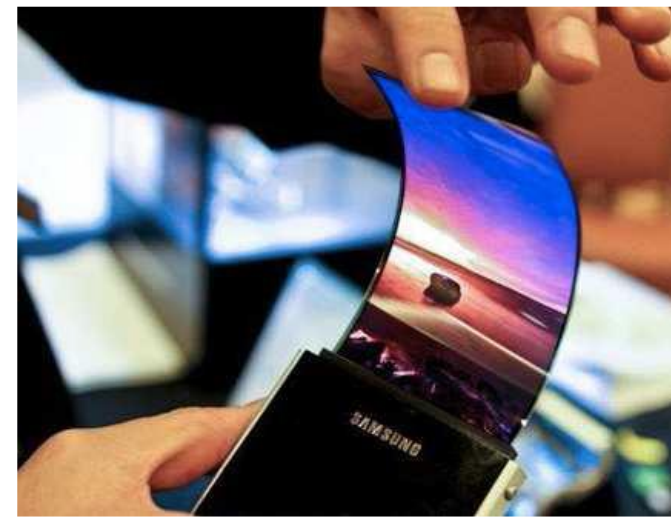

(a)

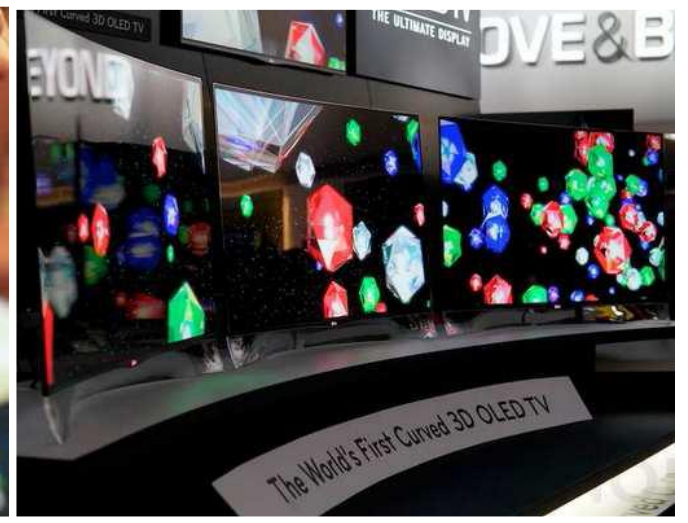

(b)

Gambar 18. (a) Foldable OLED Smartphone (Samsung galaxy S4); (b) TV OLED melengkung pertama.

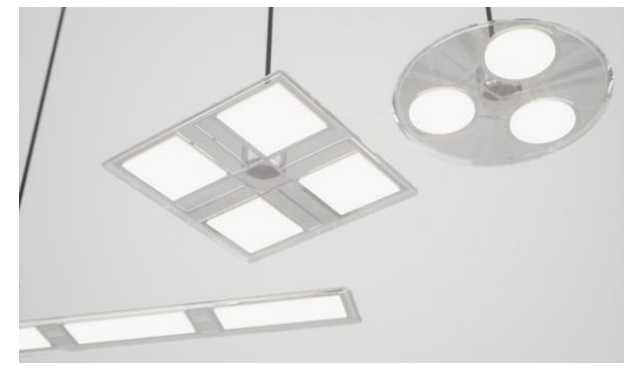

(a)

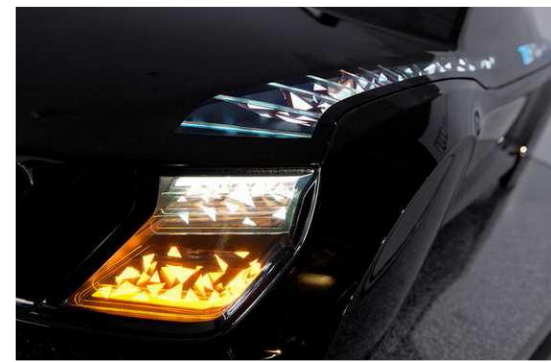

(b)

Gambar 19. (a) White OLED flat Lamps; (b) White (dan warna lain) OLED untuk lampu mobil.

\section{Kesimpulan}

Dapat disimpulkan bahwa OLED akan lebih baik apabila telah melewati tiga proses penting, yaitu injeksi muatan, pengangkutan muatan, dan emisi cahaya. Unjuk kerja OLED memenuhi kebutuhan target utama yang diperlukan dalam aplikasi tampilan. Tampilan passive-Matrix OLED sangat menarik karena bentuknya sangat sederhana. Pengembangan fleksibel OLED dengan kecenderungan pemakaian daya lebih rendah, dan lebih ringan menawarkan banyak keuntungan terhadap pemakaian LCD dan LED. Substrat dan lapisan organik pada OLED lebih tipis, lebih ringan, lebih lentur, dan lebih terang dibanding dengan lapisan kristalin pada LED dan LCD. OLED mudah diproduksi dan karena pada dasarnya OLED adalah plastik maka bisa dibentuk pada lembaran tipis dan lebar.

\section{Daftar Pustaka}

[1] A. Singh, H. L. Vishwakarma, "Organic Light Emitting Diodes: Materials, Fabrications and Applications," International Journal of Science and Research," vol. 3, issue 6, h. $577-581$, June 2014.

[2] A. Khazanchi, A. Kanwar, L. Saluja, A. Damara, V. Damara, “OLED: A New Display Technology," International Journal Of Engineering And Computer Science," vol. 1, issue 2, h. $75-84,2012$.

[3] Y. Karzazi, "Organic Light Emitting Diodes: Devices and Applications," J.Mater. Environ. Sci., vol. 5, no.1, h. 1 - 12, 2014. 


\section{Internet:}

[4] http://en.wikipedia.org/wiki/Oled

[5] http://www.oled-info.com/oledTV

[6] http://www.jmaterenvironsci.com

[7] http://www.extra.research.philips.com/euprojects/olla/

[8] http://expertscolumn.com/content/oled-advantages-and-disadvantages

[9] http://www.cosc.brocku.ca/Offerings/3P92/seminars/OLED_Organic.ppt 